\title{
Trust and the Choice Between Housing and Financial Assets: Evidence from Spanish Households*
}

\author{
Mayssun El-Attar ${ }^{\dagger} \quad$ Markus Poschke ${ }^{\ddagger}$
}

September 2010

\begin{abstract}
Trusting behavior has been shown to affect households' portfolio choice between risky and risk-free financial assets. We extend the analysis to include the dominant component of households' portfolios, real estate. Using data from the European Social Survey, we estimate individual-level trust by applying a hierarchical item response model. Combining these estimates with data on Spanish households' financial decisions from the Survey of Household Finances (EFF), we show that households with less trust invest more in housing and less in financial assets, in particular risky ones. Trust thus may drive not only (limited) stock market participation, but financial development more generally.
\end{abstract}

JEL codes: D1, D8, Z1

Keywords: housing, trust, portfolio choice, item response models

\section{Introduction}

While most of the literature on portfolio choice has focussed on holdings of risky assets, the asset class that actually dominates private asset holdings is real estate. This is true across countries, as illustrated e.g. by Bover et al. (2005) for Italy, Spain, the UK and the U.S.. Figures 1(a) and 1(b) show portfolio composition across the Spanish wealth distribution in terms of Euro values and

${ }^{*}$ The authors would like to thank the Bank of Spain and in particular Olympia Bover for channeling the blind use of regional information and protecting the confidentiality of the EFF, following up Mayssun El-Attar's stay in the Research Division as a visiting Ph.D. researcher. They would also like to thank Bernard Dumas, Richard Spady, Luigi Guiso, Pedro Gete, Carolina Villegas, Christoph Winter and an anonymous referee for helpful comments and suggestions.

${ }^{\dagger}$ CeMMAP, IZA

${ }^{\ddagger}$ McGill University, IZA, CIREQ 
portfolio shares. It is striking that for almost $90 \%$ of households, real estate constitutes the dominant portfolio component. In fact, among home owners, only the richest households hold any significant amount of financial assets at all. They are also the main holders of risky assets; Figure 2 shows that barely any lower and middle class households hold risky assets. While at $82 \%$ the homeownership rate is slightly higher in Spain than in Italy, the UK or the U.S., where it lies around $70 \%$, real estate constitutes the most important portfolio component in these countries, too (Bover et al., 2005). Given the dominance of real estate in most households' portfolios, it is important to include it when analyzing portfolio choice.

In contrast to this, the focus of the literature on household portfolio decisions has been on the choice between risky and non-risky assets, and in particular on explaining limited stock market participation. This is also true for the recent literature that has shown the importance of social attitudes for portfolio choice decisions. For instance, Duflo and Saez (2002) and Hong et al. (2004) have studied the effect of social interactions (as a mechanism through which information can be transmitted) on participation in pension plans and in the stock market, respectively ${ }^{1}$

Guiso et al. 2004a, 2008 have studied the effect of trusting behavior on portfolio choice decisions. They argue that an investor's perception of the risk of an asset depends not only on the asset, but also on subjective characteristics of the investor. The reason is that the return may be affected by (mis)behavior of other parties. As a consequence, trust in others matters for the subjective expected return, and less trustful individuals hold fewer stocks. These authors find empirical support for this hypothesis using data from Italy and from the Netherlands. In a similar vein, Duarte et al. (2010) find that a counterparty's

\footnotetext{
${ }^{1}$ Other explanations of limited stock market participation that have been advanced are the presence of background risk (Heaton and Lucas, 2000), non-standard preferences (Barberis et al. 2001), fixed entry costs (Vissing-Jorgensen, 2002), learning costs (Bayer et al. 2009 Bernheim and Garrett 2003) and the cost of awareness (Guiso and Japelli 2005). All of these papers consider financial assets only. Brueckner (1997), Campbell and Cocco (2003) and Cocco (2004) analyze the influence of the predominance of housing in most portfolios on portfolio choice and stock market participation but do not link this to trust or to other social attitudes.
} 
perceived trustworthiness affects investors' lending decisions.

Pursuing this argument further, the first main contribution of this paper is to include real estate in the analysis of trust and portfolio choice. We start by sketching a very simple model where housing, while constituting an investment, also yields flow utility from use (Section 2). Demand for housing is determined simultaneously with the demand for other assets. If trust affects the expected return of financial assets, it also influences housing investment $2^{2}$

Including all important asset classes in the analysis helps pinning down more precisely the effect of trust. In particular, including housing as a non-financial asset allows verifying whether trust affects only investment in risky assets or investment in financial assets generally. The model suggests as the most plausible scenario the one where generalized trust affects all types of financial assets, but has a stronger effect on risky assets, because of a larger scope for misbehavior by other parties.

To investigate the effect of trust empirically, we use data from the European Social Survey (ESS) and from the Survey of Household Finances (EFF) conducted by the Bank of Spain. The ESS contains information on personal and demographic characteristics and several questions on trust. The EFF also contains information on personal and demographic characteristics, plus detailed information on asset holdings. The distinct advantage of using this survey for our analysis is that it is representative of the entire wealth distribution. In particular, rich households - as shown, the only ones holding significant shares of financial assets - are oversampled, and their asset holdings are not top-coded.

While the EFF does not contain information on trust, we can still use it by proceeding in two steps. First, using data from the ESS, we estimate probability distributions of trust for a large set of very detailed demographic groups defined by common age, gender, education, income group, household size, characteristics

\footnotetext{
${ }^{2}$ There is a large literature on real estate economics with models involving features such as minimum house size, indivisibilities, transaction costs, the possibility of renting, mortgages etc.; see e.g. Cuoco and Liu (2000), Flavin and Yamashita (2002), Faig and Shum (2002), Cocco (2004), $\mathrm{Hu}(2005)$ and Yao and Zhang (2005). While these models are much richer than the one we use, none of these papers analyzes the role of trust.
} 
of parents etc. We then exploit the variation in trust between these groups to identify the effect of trust on the share of wealth invested in housing, in financial assets and in risky financial assets.

For this two-step approach, it is particularly important to have a good measure of trust in the first step. The second main contribution of the paper thus consists in measuring trust very carefully, using a new item response model proposed by Spady (2007). This method is highly flexible and imposes very few parametric assumptions. It also allows us to use information from a broad set of questions on trust and to exploit information contained in personal and demographic characteristics. As a result, we can avoid using distant proxies and are not restricted to using single specific questions, which necessarily only capture a single aspect of trust, as often seen in the literature (see e.g. Guiso et al. 2004a. 2008, 2009). Moreover, the method weights different questions to reflect their differential information content, unlike a simple average across questions as used e.g. by Fatih et al. (2007). Our measure thus encompasses several dimensions of trust, better capturing the complexity of the concept. Using information from more than one question also yields a more precise measure, thereby reducing measurement error (see e.g. Schennach, 2004). Since latent variables are already difficult to measure, this is very valuable.

Results of the empirical analysis show that trust reduces the share of wealth invested in real estate and raises that invested in financial assets, with a particularly strong effect on the share of risky assets. While we also reconfirm Guiso et al.s $\mathrm{s}$ (2008) finding that trust raises the share of financial assets held in risky assets, our results show that the effect of trust is not limited to risky assets, but is broader and benefits all financial assets.

We also find that results using a measure of trust based on one question only yields qualitatively similar but statistically insignificant results. Using our measure of trust, in contrast, the effect of trust on holdings of each asset class is strongly statistically significant, suggesting an important gain in precision from our approach to measuring trust. Our results are also robust to using measures of trust based on the average of responses to different questions on trust or a 
measure computed using principal components analysis.

Finally, we show that the effect of trust is smaller for more educated or wealthier households. This is in line with related findings in the literature showing that wealthier investors display less "irrational" behavior (see e.g. VissingJorgensen, 2003). Still, even once the effect of trust on the real estate portfolio share is allowed to vary with education or wealth, it is negative for almost all households in the sample.

The paper is structured as follows. Section 2 presents a simple theoretical model of trust and portfolio choice. Section 3 shows the structural representation of the empirical model and describes our approach to measuring trust. The data is presented in Section 4. In Section 5, we analyze the determinants of trust and then present the empirical results on the effect of trust on portfolio choice. Finally, Section 6 concludes.

\section{A Simple Model}

In this section, we analyze a simple problem of portfolio choice between investment in housing and in other assets to explore the link between individual trust and asset allocation. Suppose that agents value consumption $c_{t}$ and housing $h_{t}$ with a period utility function $u\left(c_{t}, h_{t}\right)$ with partial derivatives $u_{c}(\cdot), u_{h}(\cdot)>0$ and $u_{c c}(\cdot), u_{h h}(\cdot)<0$ and with $\lim _{c \rightarrow 0} u_{c}(\cdot)=\lim _{h \rightarrow 0} u_{h}(\cdot)=\infty$, where $u_{x}$ denotes the partial derivative of $u$ with respect to a variable $x$. Let the relative price of housing in units of the consumption good be $q_{t}$. Because of very high marginal utility of the first units of housing, all households with positive income will choose to hold some housing ${ }^{3}$ Households maximize the expected discounted sum of their utility stream, discounting future utility using a discount factor $\beta$. Their income $w_{t}>0$ follows an exogenous process. They can save by investing in housing or in two types of financial assets; a risky asset that yields a stochastic gross return $r_{t}$ with expected return $\mathbb{E}_{i}\left[r_{t}\right]$ and a "safe" asset

\footnotetext{
${ }^{3}$ In the data, a small fraction of households does not own any housing. This can be explained by indivisibilities: there is a minimum house size; agents with too small endowments to afford this resort to renting. As in Cocco (2004), we abstract from this in this section. $\mathrm{Hu}$ (2005) and Yao and Zhang (2005) study the effects of renting on portfolio decisions.
} 
that is free of idiosyncratic (asset-specific) risk that is expected to yield a gross return of $r_{i t}^{f}<\mathbb{E}_{i}\left[r_{t}\right]$.

Expected returns to investment differ across individuals $i$ because of differences in trust. All investments require interacting with a counterparty that may potentially misbehave, reducing the return to the investment. Trust in the counterparty implies a lower assessment of its propensity to misbehave. For this reason, it is often modeled as reducing the probability the investor attaches to the counterparty absconding or embezzling the investment (see e.g. Guiso et al. 2004a). In this paper, we measure agents' generalized trust in others. Denote it by $\tau$. Agents with low generalized trust attach higher probabilities to negative events such as being cheated by their bank (e.g. because it charges unjustified or exaggerated fees or gives them bad investment advice), by their broker (who could embezzle the funds invested; the setting used in Guiso et al. (2004a) ) or by other parties involved in the investment. A higher probability of these negative outcomes reduces expected returns from investment.

The impact of differences in trust on expected returns can differ across assets. It is well known that risky investments can give rise to more incentive problems than safe ones. In fact, the assets classified as safe in our empirical analysis (pensions, life insurances and liquid assets such as cash, bank deposits and chequeing accounts) are subject mainly to systemic concerns about inflation or stability of the financial system. For risky assets, these and additional concerns apply. If this is the case, $\partial \mathbb{E}_{i}\left[r_{t}\right] / \partial \tau>\partial r_{i t}^{f} / \partial \tau$. While in principle, trust may also affect the perceived return to investing in housing, we abstract from this possibility to keep the presentation simple 4

The way trust is modeled here, it is closely related to the risk of an investment. However, the two notions are distinct. Risk is a property of the investment. Trust, in contrast, is a property of the investor that affects the

\footnotetext{
${ }^{4}$ In real estate investments, the assets are tangible and can be inspected, reducing the scope for misbehavior. Moreover, the counterparties are often known in person (in particular for residential real estate), so that less generalized trust is required. (Trust in a particular person may still be necessary.) Results below indeed turn out to imply that the expected return to housing is less sensitive to trust than the expected return to risk-free and risky financial assets, or $\partial \mathbb{E}_{i}\left[q_{t} / q_{t-1}\right] / \partial \tau<\partial r_{i t}^{f} / \partial \tau<\partial \mathbb{E}_{i}\left[r_{t}\right] / \partial \tau$.
} 
perceived distribution of asset returns, with an impact that can depend on the asset. It is also distinct from an investor's risk aversion, which is about the evaluation of outcomes, not the probability attached to them. Nothing prevents a very risk averse investor from also being very trusting, and in effect, the empirical results show that both trust and risk aversion matter. Finally, they also show that trust matters even for more market-savvy investors who are likely to have better knowledge about past patterns of returns. The effect of trust thus also is distinct from that of knowledge about financial markets.

Assets carried over from the previous period, including housing, can be sold costlessly, and the proceeds can be reinvested or consumed. Since assets are perfectly fungible, the pertinent individual state variable at time $t$ are total assets at the beginning of the period. Let this be $a_{t}$ and let beginning of period holdings of housing be $\bar{h}_{t}$. With assets $a_{t}$ in hand, households then choose current consumption $c_{t}$, housing $h_{t}$ and new holdings of the risky and the riskfree asset $s_{t+1}$ and $m_{t+1}$. Assets at the beginning of the period or cash on hand (Deaton, 1991) are then given by $a_{t} \equiv w_{t}+r_{t} s_{t}+r_{t}^{f} m_{t}+q_{t} h_{t-1}$.

To write the problem recursively, denote next-period values by primes and define the transition equation $\bar{h}^{\prime}=h$. Agent $i$ then solves

$$
V(a)=\max _{c, h, s^{\prime}, m^{\prime}}\left\{u(c, h)+\beta \mathbb{E}_{i} V\left(a^{\prime}\right)\right\}
$$

subject to the budget constraint

$$
c+q h+s^{\prime}+m^{\prime}=w+r s+r^{f} m+q \bar{h}
$$

to the realizations of the income process, and given initial assets 5

In this context, the individual's inter- and intratemporal decisions cannot be separated because the housing choice enters both of them: housing yields utility, but is also a way of transferring resources to the future. Using the firstorder conditions and the envelope condition for the agent's problem, the Euler

\footnotetext{
${ }^{5}$ Assuming that returns are low enough relative to $\beta$ to make the problem bounded, it follows from standard results that a unique value function $V$ exists and that it is increasing and differentiable in $a$.
} 
equations for holdings of the three assets are

$$
\begin{aligned}
& u_{c}(c, h)=u_{h}(c, h) / q+\beta \mathbb{E}_{i}\left[u_{c}\left(c^{\prime}, h^{\prime}\right) q^{\prime} / q\right] \\
& u_{c}(c, h)=\beta \mathbb{E}_{i}\left[u_{c}\left(c^{\prime}, h^{\prime}\right) r^{\prime}\right] \\
& u_{c}(c, h)=\beta \mathbb{E}_{i}\left[u_{c}\left(c^{\prime}, h^{\prime}\right)\right] r_{i}^{f^{\prime}} .
\end{aligned}
$$

These three equations govern asset allocation. The first condition shows that, apart from its investment return, housing also yields current utility. For the other assets, we have the usual Euler equations. Through expected marginal utility, trust enters all conditions including the one for housing as long as there is some investment in financial assets.

The right hand sides of these three equations equal the expected discounted marginal return to investing in the three assets. At an interior solution, these are all equal. As the marginal utility of housing decreases in $h$, the right hand side of Equation (3) is a decreasing function of $h$. Together with finite current marginal utility due to $w>0$ and the Inada conditions, this implies a strictly positive and finite choice of housing every period if $q^{\prime} / q$ is low enough compared to the expected return on financial assets. (If $\mathbb{E}_{i}\left[u_{c}\left(c^{\prime}, h^{\prime}\right) q^{\prime} / q\right]>\mathbb{E}_{i}\left[u_{c}\left(c^{\prime}, h^{\prime}\right) r^{\prime}\right]$ for all asset allocations, there is no investment in financial assets.) Because of the high marginal utility of the first units of housing, agents allocate the initial units of their savings to housing. They then buy housing until its return falls to the level of the return of financial assets. Remaining savings are invested in financial assets. Relatively poor agents thus hold only housing, and only rich agents hold a substantial amount of financial assets.

Trust affects the portfolio choice. An increase in an agent's level of generalized trust raises expected returns on both financial assets, but not on housing. As a result, optimal holdings of housing fall, and holdings of both financial assets increase. If $\partial \mathbb{E}_{i}[r] / \partial \tau>\partial r_{i}^{f} / \partial \tau$, the share of risky assets increases not only as a fraction of wealth but also as a fraction of financial assets.

Evidently, other factors besides trust may also affect portfolio choice. One such factor is risk aversion, which is present in the model in the standard way. Others, such as age or the number of children, are omitted from the model be- 
cause they are not directly related to the analysis of trust, but may nevertheless affect portfolio choice. Portfolio shares thus are a function of trust and these other determinants. Whether the effect of trust is significant, and which type of trust matters, can be inferred from regressions of the portfolio shares on a measure of trust and other pertinent factors. If generalized trust in others, and thereby in the financial system, strongly affects portfolio choice, we should see the share of housing and those of both types of financial assets in wealth moving in opposite directions as trust changes. Differences in trust in intermediaries for risky products, in contrast, should move the shares of risky and safe assets in wealth in opposite directions, with the share of housing moving like that of safe assets. Note that to obtain the effect of trust on financial assets overall, needed to distinguish these cases, it is required to include housing in the analysis, as risky and safe assets as a share of financial assets may move in the same way for changes in either type of trust if $\partial \mathbb{E}_{i}[r] / \partial \tau>\partial r_{i}^{f} / \partial \tau$. We next describe our empirical approach to testing the impact of trust on portfolio choice.

\section{Empirical Approach}

The main challenge in measuring the effect of unobservable latent attitudes such as trust on economic outcomes lies in measuring them. One of the main contributions of this paper therefore lies in careful measurement of trust. This section first presents the causal structure we presuppose and then discusses the implementation of the analysis, in particular the measurement of trust.

\subsection{Structural Representation}

Figure 3 shows a diagram of the underlying process we have in mind. Suppose that every individual has some amount of trust. An individual's trust directly causes the responses to certain survey questions. It also has an effect on the individual's behavior, in particular, the portfolio choice decision. Demographic and personal characteristics may also be informative about the way in which trust is distributed in a population; individual characteristics and experiences as 
well as community characteristics can be related to how much people trust each other. We assume that these characteristics do not affect the answers directly. If they have an effect on the responses, this is through their effect on trust. They can however affect the behavior of the individual (e.g. portfolio choice) directly.

The model of trust just described has the following structural representation:

$$
\begin{aligned}
s_{k} & =h_{k}\left(X^{s}, X^{\tau}, \tau, \mu_{k}\right) \\
R_{m} & =g_{m}\left(\tau, u_{m}\right), \quad m=1, \ldots, M \\
\tau & =t\left(X^{\tau}, Z, \varepsilon\right)
\end{aligned}
$$

where $s_{k}$ is the household's share of wealth invested in asset class $k$ (e.g. housing), $R_{m}(m=1, \ldots, M)$ are the responses to $M$ survey questions, $\tau$ is a measure of trust and assumed to be univariate, $X^{\tau}$ are covariates (age, number of members in the household, income and education, marital status and family background) related to trust, $X^{s}$ are other covariates affecting only the portfolio choice decision, and $Z$ are 17 regional dummies. The choice of covariates is discussed in Section 4 In accordance with the model, the first equation posits that portfolio shares depend on a household's level of trust and on personal characteristics through an asset-specific function $h_{k}(\cdot)$. It also allows for an error term $\mu_{k}$. The second equation states that the responses to survey questions are functions only of the latent attitude and a question-specific error term $u_{m}$. We assume that for all $m, u_{m} \sim U(0,1)$ and that $g_{m}(\cdot)$ is weakly increasing in $u_{m}$ and strictly increasing in $\tau$. It is also assumed that $u_{i} \perp u_{j} \forall i \neq j$ and that $u_{i} \perp \tau \forall i$. This implies that conditional on $\tau$, the responses are independent $\left(R_{i} \perp R_{j} \mid \tau\right)$.

Finally, trust itself may be correlated with a subset of personal and demographic characteristics. $\varepsilon$ is the error term in this relationship. We assume that individual characteristics may affect the latent variable $\tau$, but do not affect the measurements $R_{m}$ directly, and consider the linear case

$$
\tau=t\left(X^{\tau}, Z, \varepsilon\right)=X^{\tau} \gamma_{1}+Z \gamma_{2}+\varepsilon
$$


Define $W \equiv\left(X^{\tau}, Z\right)$ and $\gamma=\left(\gamma_{1}, \gamma_{2}\right)$ and assume that $\varepsilon \sim N(0,1)$ and that $\varepsilon \perp W$. Also assume that $u_{m} \perp \varepsilon, u_{m} \perp W, \mu \perp \varepsilon$ and $\mu \perp W$.

\subsection{Empirical implementation}

If trust was observable, estimating Equation (6) would be straightforward. However, although it is very informative about personal and demographic characteristics, the EFF does not contain direct information on trust. Therefore the approach we take is to perform the estimation in two steps using two datasets:

Step I: Using Equations (7) and (8), we obtain an estimate of individuals' trust and an estimate of $t(\cdot)$ applying the item response theory model described in Section 3.3 to data from the ESS. To ensure that the estimate of $t(\cdot)$ is as precise as possible, we control for many personal and demographic characteristics. The highly flexible estimation method proposed by Spady (2007) has proven very useful for this.

Step II: Using the estimate of $t(\cdot)$ from Step I, we construct a measure of trust using the personal and demographic information contained in the EFF. We then estimate the effect of trust on portfolio choice decisions using a linear version of Equation (6). (The linearity restriction is easy to relax.) Since there is an equation for each asset class, we have a system of equations with the same regressors. The efficient estimator for this setting is single-equation OLS (see Green, 2003, p. 344) or, for our case with a censored dependent variable, a Tobit model 6

The identification of the effect of trust on portfolio choice does not only rely on the functional form of the estimate of $t(\cdot)$, but also on additional instruments provided by the regional dummies $Z$. From the measurement of trust in the first step, we know that they are correlated with trust (see Table 1 below), but we assume that once we control for regional housing prices and regional

\footnotetext{
${ }^{6}$ One may think that there also is an adding up condition across asset classes if the dependent variables add to one. This is not the case for all the households; some households invest in other asset classes like jewels, art work or business related to self-employment which we disregard. Therefore, we do not impose cross-equation restrictions.
} 
financial development, they are not correlated with the portfolio choice decision.

As a robustness check, we also perform Step II using instrumental variables, employing instruments from Tabellini (2005) 7

\subsection{Measuring trust using an item response model}

Given the structural representation described in Section 3.1. Step I of our approach consists in obtaining estimates of each individual's trust and of $t(\cdot)$ by applying an item response model. Item response theory (IRT) models have been widely used in psychometrics to measure latent traits like ability, trust or other attitudes using test results or survey outcomes 8 They allow to obtain quantitative measures of these concepts using all the available information, permit the measurement of several dimensions of the latent attribute, and do not require imposing excessive parametric assumptions. While confirmatory factor analysis has been used for the same purposes as IRT models (see e.g. Carneiro et al. 2003 Heckman et al. 2006), IRT models deal with discrete outcomes in a more straightforward way 9 In our case, we obtain the individual measure of trust using 8 different questions (items) on different aspects of trust, with 3 categorical responses each. In this case there are $3^{8}=6561$ cells or possible combinations of responses (response patterns). When using such information, IRT models are a very useful tool.

The three main assumptions made in Section 3.1 that underly our IRT model are: (1) Unidimensionality: The questions used should reflect only the individual's general trust, so the responses are determined by a single attitude only. (2) Local Independence: The responses to the different questions on trust are stochastically independent of each other given the individual's latent trait. This

\footnotetext{
${ }^{7}$ Using generated regressors always raises issues of consistency of the estimates and of the estimated standard errors. In the present case, the coefficient estimates are consistent and standard inference is correct for testing the hypothesis whether the coefficient on trust is zero. ${ }^{8}$ See Steele and Goldstein (2007) for a recent review of parametric hierarchical IRT.

9 Takane and de Leeuw (1987) show, under specific assumptions, the formal equivalence between the marginal likelihood of an item response model and the likelihood of a confirmatory factor analysis. In that case, the parameters obtained using the item response model are equivalent, under some transformation, to the ones obtained using confirmatory factor analysis.
} 
implies that the correlation between two items can only be attributed to the individual's level of trust. (3) Monotonicity: Individuals with higher levels of trust are more likely to choose higher answers (given the coding of the questions that we use).

The method we use also exploits information about the latent attitude contained in personal and demographical characteristics. Equation (9), which states that at an individual level, trust is a function of personal characteristics and an error term, implies that there is a distribution of attitudes that is conditional on personal characteristics. Denote it by $\phi(\tau \mid W ; \gamma)$. The likelihood function for responses to $M$ survey questions by $N$ independent individuals then is

$$
\begin{aligned}
& L\left(R_{11}, R_{21}, \ldots, R_{M 1}, \ldots, R_{1 N}, \ldots, R_{M N} \mid W ; \gamma\right) \\
& \quad=\prod_{n=1}^{N} \int p\left(R_{1 n}, R_{2 n}, \ldots, R_{M n} \mid \tau\right) \phi(\tau \mid W ; \gamma) \mathrm{d} \tau \\
& \quad=\prod_{n=1}^{N} \int p\left(R_{1 n} \mid \tau\right) p\left(R_{2 n} \mid \tau\right) \ldots p\left(R_{M n} \mid \tau\right) \phi(\tau \mid W ; \gamma) \mathrm{d} \tau
\end{aligned}
$$

where the second equality follows from the local independence assumption.

The conditional response probabilities $p\left(R_{m} \mid \tau\right)$ in the likelihood function are determined by the function $g_{m}\left(\tau, u_{m}\right)$ in Equation (7). To capture the discrete nature of responses, $g_{m}(\cdot)$ is specified as a threshold function in IRT models. For example, $g_{m}\left(\tau, u_{m}\right)=2$ if $G_{1}(\tau)<u_{m} \leq G_{2}(\tau)$. With 3 possible answers to each question and a uniform distribution for $u$, there are 2 free thresholds. Their dependence on $\tau$ captures the effect of trust on the response. Following Spady (2007), we estimate the threshold functions $G_{j}(\tau)$ as one minus the distribution function corresponding to an exponential tilting of second degree of the uniform density. Although parametric assumptions are needed for identification, this approach is much more flexible than traditional ones that use functions such as the logistic function or the normal.

For illustration, estimates of $p\left(R_{m} \mid \tau\right)$ are shown in Figure $44^{10}$ Each box shows the probability of answering 1,2 or 3 to a given question as a function

\footnotetext{
${ }^{10}$ For more information on computation, see Appendix A
} 
of trust. As an example, take the first box of Figure 4. There are two lines. The distance between the $\mathrm{x}$-axis and the first line indicates the probability of answering 1 in item (question) 1 ("Would you say that most people can be trusted?"), the distance between the first line and the second line indicates the probability of answering 2 in item 1, and the distance between the second line and 1 indicates the probability of answering 3. Table 1 shows estimates of $\gamma$, the effect of personal characteristics on an individual's trust. These estimates are discussed in detail in Section 5 ,

The measure of trust resulting from this item response model encompasses several dimensions of this latent trait. By using eight items in our measurement, many aspects of trust are captured. This makes the measure more reliable in two ways. Firstly, a broadly-based measure is more reliable in the sense that it captures better the complexity of a latent trait like trust. But this is not the only advantage, as the measure is also more reliable from a statistical point of view. Considering that each one of the questions about trust is a proxy for trust, i.e. a measure of trust that contains measurement error, using only one of these measures leads to regression coefficients of trust on portfolio shares that are biased towards zero (attenuation bias). The econometric literature has suggested the use of repeated observations of the mismeasured regressor to address this bias (see e.g. Schennach, 2004). Using different proxies for a single concept, as we do, helps fight the same problem in our case.

\section{Data}

The empirical analysis combines data from two sources, the European Social Survey and the Spanish Survey of Household Finances. To measure trust, we use the second wave of the European Social Survey (ESS). The ESS is a recent data set covering 25 European Countries in 2004. In this paper we use the information related to Spain. The ESS provides rich information on several aspects of interest to social scientists. In the 2004 round, the questionnaire includes for the first time a module on "Economic morality: Trust and interactions be- 
tween producers and consumers". This module is designed to investigate the normative and moral culture of markets and consumption in European countries. It is useful for us because it has some questions about the level of trust and confidence in business and state/government institutions.

In addition, the ESS also contains information about some demographic variables that we include in the estimation. These variables capture differences in potential experiences faced during life and may therefore provide further information about attitudes that our measurement method presented in Section 3.3 can capture. Concretely, we include age, gender, education, employment status, income, marital status, the number of members in the household, the region of residence and include a dummy indicating whether the respondent's father had a professional occupation. Age allows capturing that attitudes might change over the life cycle due to personal experience. There may also be cohort effects linked to national and global developments like e.g. financial crises. Since our data set is only a cross section, it is unfortunately impossible to disentangle life cycle and cohort effects. The income coefficient should mainly reflect luck, as most other determinants of income, in particular education, are also included as controls. It seems reasonable to expect that luck, and thus past experience with others, may affect trust. Table 2 contains summary statistics of the personal and demographic characteristics we include. Our data include 1156 men and women older than 18 .

To measure trust, we use eight pertinent survey questions (items). (For the original wording of these items see Appendix B. Summary statistics of the responses to these items are presented in Table 3. The responses are recoded such that each item has three possible answers on a scale of 1 to 3 . A higher score corresponds to a higher level of trust. Answering behavior varies over these items. For instance, the mean for the question "Can public officials be trusted?" is 2.178. In contrast, the mean for the question "Can politicians be trusted?" is only 1.522. These differences indicate that different items carry information on respondents' attitudes to a varying degree. Thus, by focussing on just one or on a narrow subset of these items, valuable information might be 
lost. This is also indicated by the pairwise correlation coefficients for the items shown in Table 4 correlations are positive but far from perfect. This again illustrates that combining items can lead to a better measure of trust.

For the analysis of portfolio choice decisions we use the 2002 wave of the Spanish Survey of Household Finances (EFF). This survey contains information about incomes, assets, debt and consumption at the household level ${ }^{11}$ A distinguishing feature of the EFF is that the wealthiest households are oversampled and their asset holdings are not top-coded. So the upper quantiles of the wealth distribution can also be studied. Since they hold most of the assets, in particular financial assets, this is very important.

In the subsequent analysis, we will concentrate on the asset classes real estate, financial assets, risky assets and cash. Table 5 shows descriptive statistics for holdings of these assets. Real estate is the largest portfolio component and makes up most of non-financial assets. In line with the model, financial assets can be classified as risky or non-risky. Risky assets consist of listed and unlisted shares, fixed-income securities and mutual funds. Non-risky assets consist of pensions, life insurances, and liquid assets (accounts and deposits usable for payments) or "cash". In this category, we focus on cash as the main discretionary component 12 More detailed definitions of the asset classes are given in Appendix C. Descriptive statistics of the personal and demographic characteristics in our EFF data are shown in Table 6

\section{Results}

This section first presents the estimates of trust and its relationship to personal and demographic characteristics, and then explores the impact of trust on portfolio choice.

\footnotetext{
${ }^{11}$ For a detailed description of the survey see Bover (2004). While the EFF and ESS data used do not cover exactly the same time period (the field work for the ESS spanned October 2003 to September 2004, that for the EFF (October 2002 to May 2003), we do not expect this to matter much since trust changes only slowly.

${ }^{12}$ Holdings of pensions and life insurances are not much affected by trust (results not shown). Moreover, the determinants of take-up of these savings vehicles have been studied extensively.
} 


\subsection{The Estimates of Trust}

The method described in Section 3.3 provides an estimate of trust for every individual in our ESS sample, together with estimates of the relationship of personal and demographic characteristics to trust. These estimates are shown in Table 1 and can be interpreted in a ceteris paribus sense relative to a reference person 13

The factor that affects trust most strongly is the level of education. Higher levels of education are associated with significantly higher levels of trust. We also find a significant effect for the different income levels. Richer and poorer households both tend to exhibit lower levels of trust than middle-income households. Age also matters; younger and older individuals have less trust than the middle-aged, with the peak occurring at the age of 48 . This result is similar to the ones obtained by Putnam (2000) and by Glaeser et al. (2002) and consistent with their models of social capital accumulation over the life cycle. The effect of the number of household members has the same shape. Of course, taken together, these effects can neutralize or reinforce each other. For instance, high education is positively correlated with high levels of income, and their two effects can neutralize each other.

Regional characteristics such as differences in institutions or in ethnical composition also affect trust, as captured by the regional fixed effects. These coefficients show that there are substantial differences in trust across Spanish regions.

Using these estimated coefficients allows calculating the estimated distribution of the attitudes for different demographic groups. As an example, the expected level of trust for a respondent who is a 37 year old divorced male with low income and low education who lives in a household with 3 members in Cantabria is -0.426 , while it is 0.860 for a 50 year old married male with medium income and high education who lives in a household with 4 members in Madrid. We thus use the estimates to predict the levels of trust of the EFF

\footnotetext{
${ }^{13}$ The 'standardized' individual is a married and employed male of 38.92 years with secondary education and medium income who lives in a household with 3.35 members in the region of Andalucía and whose father did not have a professional occupation.
} 
survey respondents, as outlined in Section $3.2^{14}$

\subsection{Testing the Effect of Trust on Portfolio Choice}

The model presented in Section 2 predicts that individuals with more generalized trust invest less in real estate and more in all types of financial assets, measured as shares of wealth. While holdings of risky and non-risky assets should both increase with trust, which one increases more depends on how sensitive their expected returns are to generalized trust. Adapting Equation (6), the equations of interest then are:

$$
\begin{aligned}
h_{i} & =\gamma_{h \tau} \tau_{i}+\gamma_{h 1} X_{i}^{S}+\gamma_{h 2} X_{i}^{\tau}+\mu_{i}^{h}, \\
f a_{i} & =\gamma_{f \tau} \tau_{i}+\gamma_{f 1} X_{i}^{S}+\gamma_{f 2} X_{i}^{\tau}+\mu_{i}^{f a}, \\
r a_{i} & =\gamma_{r \tau} \tau_{i}+\gamma_{r 1} X_{i}^{S}+\gamma_{r 2} X_{i}^{\tau}+\mu_{i}^{r a}, \\
c_{i} & =\gamma_{c \tau} \tau_{i}+\gamma_{c 1} X_{i}^{S}+\gamma_{c 2} X_{i}^{\tau}+\mu_{i}^{c},
\end{aligned}
$$

where $h_{i}$ is the fraction of household $i$ 's wealth invested in real estate, $f a_{i}$ is that invested in financial assets, $r a_{i}$ is that invested in risky assets and $c_{i}$ is that held in cash. $\tau_{i}$ represents the estimated level of trust. This is constructed combining information on individuals' characteristics with the coefficients obtained previously using the European Social Survey. $X_{i}^{\tau}$ contains household characteristics that may affect both trust and portfolio choice (age, gender, education, income, number of household members) and $X^{S}$ contains characteristics that should only affect portfolio choice. It includes a self reported measure of risk aversion, the regional average house price per square meter in 2002 (from Ministerio de Fomento, the Department of Construction and Public Works) and regional financial development. The latter is proxied by private credit over GDP 15 We expect these characteristics to capture differences in preferences

\footnotetext{
${ }^{14}$ Of course, most of the information in estimating trust comes from the questions about trust. The significance of results in the second step depends on how much information is captured by the personal and demographic characteristics. The $R^{2}$ in a regression of trust on the these variables in the ESS is $10 \%$, which is not a bad fit in a cross-sectional setting and turns out to be sufficient for strongly significant results.

${ }^{15}$ This is a common proxy for financial development. Other proxies that have been used in the literature like the market capitalization of listed firms over GDP are not available at the regional level for Spain, as the securities market is at the national level.
} 
across households as well as possible differences in the cost of participating in financial markets.

Unfortunately, we do not have measures of other latent attitudes such as optimism or expectations about future economic conditions. Some authors, e.g. Puri and Robinson (2007) and Dominitz and Manski (2005), have found these to significantly affect participation in the stock market. Guiso et al. (2008), however, do not confirm this, and find that they do not affect the coefficient on trust in a portfolio choice regression either. Moreover, as our measure of trust relies on several specific questions about trust that are reasonably unrelated to other attitudes, we would expect them not to be a problem for the estimation in the present setting.

Table 7 shows the results of the estimated tobit regression. The first two columns show the estimates of Equations (11) and (12). Trust has a significantly positive effect on the percentage of wealth invested in financial assets and a significantly negative effect on the percentage of wealth invested in housing, bearing out the theoretical predictions.

As the effect of trust is conditional on wealth, it also applies to the richest households. Our results are thus consistent with the argument by Guiso et al. (2008) that trust could be a factor limiting financial market participation even for rich households.

Other estimates are also consistent with other straightforward theoretical predictions. More risk averse households invest more in housing and less in financial assets. Higher housing prices reduce the housing share and raise that of financial assets. The housing share falls with income and education and rises with the number of family members.

The last two columns of Table 7 show the estimates of Equations (13) and (14). Trust has a significantly positive effect on the portfolio shares of both risky assets and cash. The other coefficient estimates in these regressions are similar to those obtained for financial assets generally. The effect of trust on risky assets is stronger than that on cash. This is confirmed in Table 8 , which shows results for the same regressions, using the shares of risky assets and cash over 
financial assets (instead of wealth) as the dependent variables. The regression is set up exactly like the analogous regression in Guiso et al. (2008, Table 7) on Italian data ${ }^{16}$ and our results parallel theirs: agents with higher levels of trust hold a significantly higher share of risky assets as a fraction of financial assets. Even the magnitude of the trust coefficient we obtain is very close to that in Guiso et al. (2008), with a one standard deviation increase in trust increasing the share of risky assets over financial assets by just under 5 percentage points in both their and our results.

Other measures of trust. To assess the robustness of our results, we conduct the same regression using different alternative measures of trust (see Table 9p. For the measure Trust (single question), we simply use the response to the question, "Would you say that most people can be trusted?" The measure Trust (mean of responses) is computed using the mean of the responses to the 8 questions on trust. The measure Trust (Principal Components Analysis) consists in the first component of a principal components analysis on the 8 questions on trust ${ }^{17}$ Finally, the measure Trust (in banks) consists in the response to the question "How much do you trust financial companies such as banks or insurers?"18

Results from these regressions are shown in Table 9 In all specifications, we also control for the same variables as in Table 7, but display only the coefficient on the measure of trust. The first panel of the table reproduces results from Table 7 obtained using the IRT measure. The signs of all the estimated coefficients on generalized trust are the same as those obtained using the IRT measure of

\footnotetext{
${ }^{16}$ This implies using household financial wealth instead of net wealth, and letting income and wealth enter only linearly.

${ }^{17}$ The first component is the linear combination of the 8 questions on trust that explains most of the variation in the data. Note that standard principal components analysis has been developed for continuous data and, unlike the IRT measure, does not take into account the discreteness of our data.

${ }^{18} \mathrm{As}$ these measures are not contained in the EFF, using them requires a two-step procedure analogous to that used for our main measure of trust. In the first step, we regress the obtained measures on the same demographics used for our main measure. We use an ordered probit for this when using a single measure or the mean of the responses and an OLS regression when using the result of the principal components analysis. In the second step, we use the coefficients obtained from the first step to impute a measure of trust in the EFF data.
} 
trust. Those obtained using a single question only are not significant. This can be attributed to attenuation bias due to the presence of more measurement error in trust when only such a simple measure is used. When using the mean of responses or the measure obtained using PCA, the coefficient on cash is not significant.

Results obtained using the IRT measure thus are robust to using other measures of trust. However, recall that among these measures, the IRT measure is the only one that explicitly takes into account discreteness and that weights the different items according to their information content.

Education, wealth and trust. Does trust matter equally for everyone? The estimates on the effect of trust on portfolio choice in this section are conditional on, among other things, education and wealth. Yet it might be the case that more educated and wealthier households have more information about financial markets and a better understanding of how these markets work. Indeed, e.g. Vissing-Jorgensen (2003) shows that wealthier investors display less "irrational" behavior. Similarly, the effect of trust may vary with education or wealth.

To test this, we run the portfolio choice regressions including interactions between trust and years of education and between trust and log wealth. Results are shown in Table $10^{19}$ The first result to note is that in both cases, the sign of the coefficient on trust is unaffected by the inclusion of the interactions. The coefficient also remains highly significant (except for one case).

The interaction with education takes the opposite sign of the coefficient on trust for all asset classes, indicating that education reduces the effect of trust on portfolio choice decisions. This is particularly pronounced for risky assets. The marginal effect of trust on housing remains negative and that on financial assets positive for all households in the sample. The interaction with wealth also takes the opposite sign of the trust coefficient. Still, the coefficient on trust dominates, and the marginal effect of trust on the housing share is negative for

\footnotetext{
${ }^{19}$ The rest of the specification is the same as before, with similar results, so we only report
} the coefficients related to trust. 
almost all the households in the sample.

Education and wealth thus reduce the impact of trust on portfolio choice, possibly through greater information about financial markets or access to financial consultants. Nevertheless, trust has a significant marginal effect for almost all the households in the sample, and thus matters even when potential differences in financial education are taken into account.

Endogeneity Concerns. The identification of the effect of trust on the portfolio decisions has relied on the nonlinearity of the trust measure and on the assumption that the regional dummies are not correlated with financial decisions once we control for regional house prices and regional financial development. To be able to relax this assumption we estimate the model using instrumental variables. To instrument trust, we use the same variables as Tabellini (2005) in his influential study of the impact of culture on development: the regional literacy rate at the end of the 19th century and indicators of political institutions in the period from 1600 to 1850 . We also include the number of social and economic charity organizations in the region in 1920.20 Tabellini (2005) argues that "historically more backward regions (with higher illiteracy rates and worse political institutions) tend to have specific cultural traits today: less trust in others, less respect for others, less confidence in the individual." The validity of the historical instruments is discussed extensively in his paper, so we do not reiterate it here. Table 11 shows the values of the instruments for the Spanish regions.

The results of the IV tobit estimation are shown in Table $12{ }^{21}$ The results of the first-stage regression in the first column show that the instruments are strongly correlated with our measure of trust (see the p-value of the F-test associated to the excluded regressors). A Wald test for the instruments indicates

\footnotetext{
${ }^{20}$ The literacy rate is defined as the percentage of the population over 10 years old able to read and write in 1877 and is from Nunez (1990). Institutions are measured as constraints on the executive and are from Tabellini (2005). The number of charities is from the Anuario Estadístico de España published by the National Statistics Institute (Instituto Nacional de Estadística).

${ }^{21}$ The estimation is conducted using Amemiya's Generalized Least Squares (AGLS) estimator for tobit with endogenous regressors (see Amemiya, 1974, Newey, 1987). Again, only the trust coefficient is reported.
} 
endogeneity problems only in the regression involving risky assets. For the other regressions, the tobit estimator used above thus is more appropriate because it is more efficient. Indeed, while in some cases the coefficient on trust obtained using the instruments is larger (in absolute value) than the one obtained using OLS, the standard errors are also much larger. For the regression involving risky assets, the IV estimator is adequate. As before, it yields a strongly significant positive coefficient.

The IV estimates thus support the results obtained above. Trust significantly affects portfolio choice. Households with more trust hold less real estate and more financial assets, in particular risky ones, as a share of their wealth.

To summarize, all specifications support an effect of generalized trust on portfolio choice. Households with more trust hold a smaller share of their wealth in real estate and a larger share in financial assets. More in detail, trust has a particularly strong effect on the share of wealth held as risky assets (compared to holdings of liquid assets), implying larger holdings of risky assets as a fraction of financial assets. While this is in line with Guiso et al.s (2008) results, we can go further and show that what matters is generalized trust, not just trust in banks as intermediaries of risky assets. This is supported both by the pattern of results in the analysis of wealth portfolio shares and by results from including a direct measure of trust in banks in the analysis. To obtain these conclusions, it is crucial to include housing in the analysis and not to limit the analysis to financial assets.

\section{Conclusion}

This paper extends the analysis of the effect of trust on portfolio choice to include the most important component of households' portfolios, real estate. We show that households with less trust invest more in housing and less in financial assets, in particular risky ones. In contrast to earlier results, trust thus affects all financial assets, not just risky ones, though the effect on these is strongest. Trust hence not only constitutes a factor behind limited stock market 
participation, but may play a larger role in relation to financial development more generally.

For obtaining these results, our use of a new method for measuring latent variables (Spady, 2007) is crucial. This method is flexible and allows taking into account information from many questions on the latent attitude plus additional information from personal characteristics. The resulting measure of trust covers more dimensions of the concept than measures based on proxies or individual questions and also is more precise, reducing measurement error and producing more significant results.

\section{Appendix}

\section{A Computational procedure for measuring trust}

The estimation proceeds as in Spady (2007) and is by maximum likelihood, with the likelihood function given by 10 . The integration for the probability of a particular outcome for individual $i$ conditional on that individual's characteristics $\left(p\left(R_{1}, R_{2}, \ldots, R_{m} \mid W\right)=\int p\left(R_{1} \mid \tau\right) p\left(R_{2} \mid \tau\right) \ldots p\left(R_{m} \mid \tau\right) \phi(\tau \mid W) \mathrm{d} \tau\right)$ has been carried out using Gaussian quadrature at 200 grid points. To ensure that we can collect even the distributions with small variances, the Gaussian quadrature has been applied to 5 different segments of the grid, with the one in the middle having more points. A Newton-Raphson algorithm is used to maximize the log-likelihood function. Concretely, we use the BFGS method which builds an approximation to the Hessian instead of calculating it numerically 22

We obtain 61 parameters; 29 associated to the personal characteristics (indicating the effect on location relative to the probability distribution of the 'standardized respondent') and 32 describing the distribution functions depicted in Figure 4. Since we use exponential tilting of second degree, we estimate two parameters per line and box for the distribution functions. The parameters associated to the personal characteristics are the ones used to specify $t(\cdot)$, and

\footnotetext{
${ }^{22}$ For a general discussion about estimation procedures for this type of models, see Rodriguez (2008).
} 
therefore the parameters of interest in our case.

\section{B Original wording of the questions/items we use to estimate trust}

The following, including the footnotes, is an extract from the ESS questionnaire. Answers originally are on a scale from 0 to 10, 10 being the most trustful answer.

Generally speaking, would you say that most people can be trusted, or that you can't be too careful in dealing with people? ${ }^{23}$

Do you think that most people would try to take advantage of you if they got the chance, or would they try to be fair:24

Would you say that most of the time people try to be helpful or that they are mostly looking out for themselves?25

Please tell me how much you personally trust each of the institutions I read out.

the legal system

politicians

How much would you trust the following groups to deal honestly with people like you?

plumbers, builders, car mechanics and other repair people

financial companies such as banks or insurers.

public officials 27

\section{Definition of the financial variables used in the empirical analysis}

Total Assets is the value of Real Assets and Financial Assets.

\footnotetext{
23 "Can't be too careful": need to be wary or always somewhat suspicious.

24 "Take advantage": exploit or cheat; "fair": in the sense of treat appropriately and straightforwardly.

${ }^{25}$ The intended contrast is between self-interest and altruistic helpfulness.

26 "Builders" include all kinds of tradespeople who work on building sites.

27 "Public officials" refers to both government officials, such as customs officers and to local officials, such as housing/building regulators etc.
} 
Real Assets is the value of Real Estate, Jewellery, Works of Art, Antiques and the value of Business related to self-employed.

Real Estate is the value of Main Residence and Other Estate Properties.

Financial Assets is the value of Listed Shares, Unlisted Shares, Fixed-Income Securities, Mutual Funds, Pensions and Life Insurances and Accounts and Deposits usable for payments.

Risky Assets is the value of Listed Shares, Unlisted Shares, Fixed-Income Securities and Mutual Funds.

Cash refers to Accounts and Deposits usable for payments.

Non-Risky Assets is the value of Cash plus Pensions and Life Insurances. 


\section{Figures}

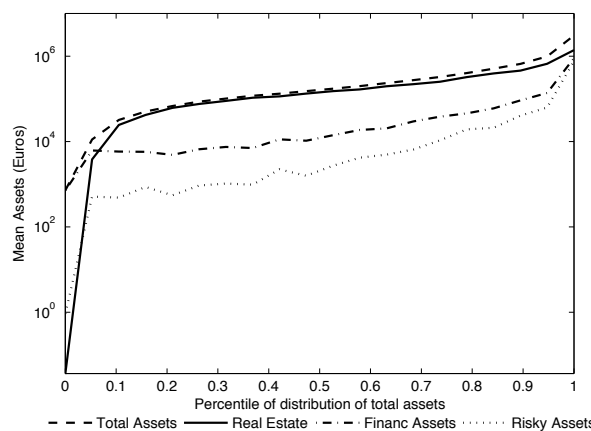

(a) values

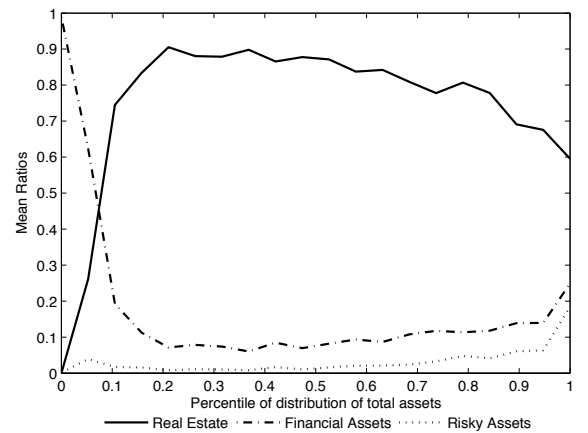

(b) shares

Figure 1: Portfolio composition across the Spanish wealth distribution.

EFF data. The figures display averages by percentile of the distribution of total assets. Real Estate is the value of Main Residence and Other Estate Properties. Financial Assets is the value of Listed Shares, Unlisted Shares, Fixed-Income Securities, Mutual Funds, Pensions and Life Insurances and Accounts and Deposits usable for payments. Risky Assets is the value of Listed Shares, Unlisted Shares, Fixed-Income Securities and Mutual Funds. 


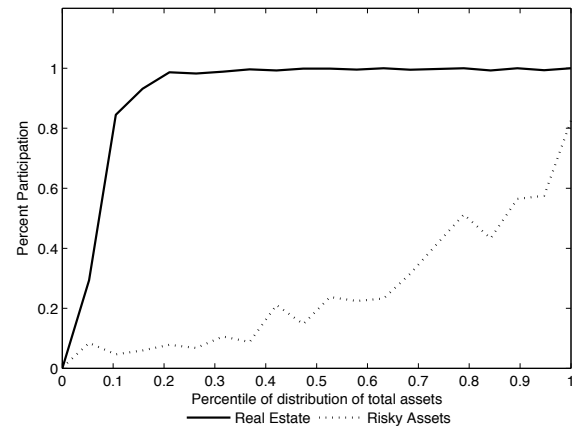

Figure 2: Participation Rates in Real Estate and Risky Assets.

EFF data. The figures display averages by percentile of the distribution of total assets. Real Estate is the value of Main Residence and Other Estate Properties. Financial Assets is the value of Listed Shares, Unlisted Shares, Fixed-Income Securities, Mutual Funds, Pensions and Life Insurances and Accounts and Deposits usable for payments. Risky Assets is the value of Listed Shares, Unlisted Shares, Fixed-Income Securities and Mutual Funds. The participation rate is 1 if a household has strictly positive holdings of the relevant asset. 


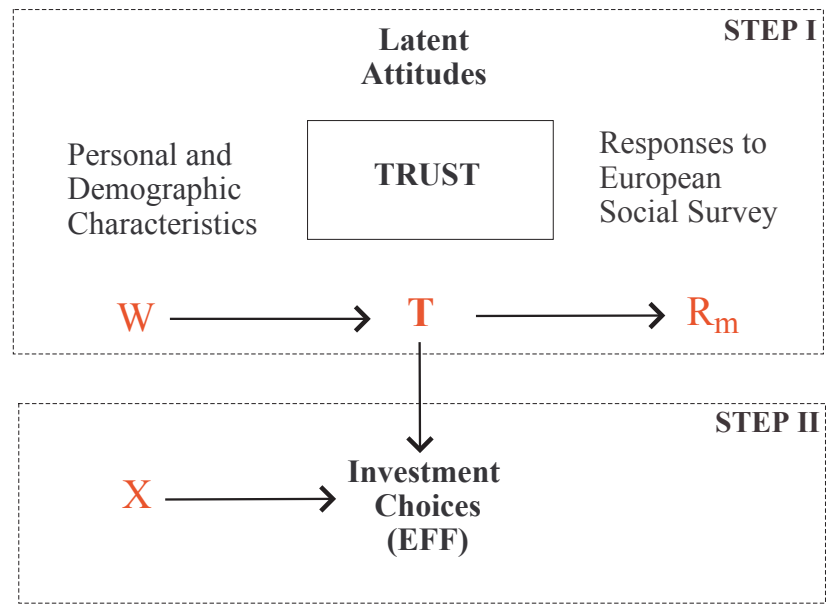

Figure 3: Structural representation.

Graphical representation of Equations (6) to (8). Investment choices depend on both personal and demographic characteristics and on trust. Responses to survey questions on trust depend only on trust. Trust itself may be correlated with personal and demographic characteristics. 


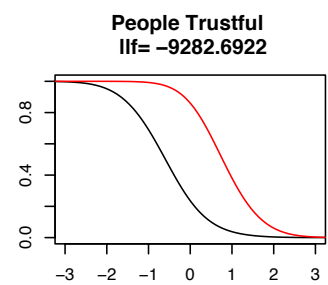

$\tau$
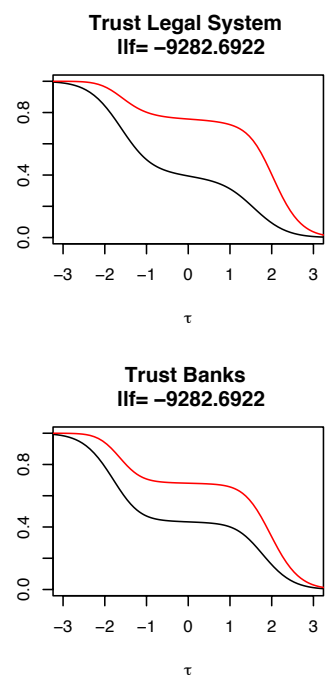

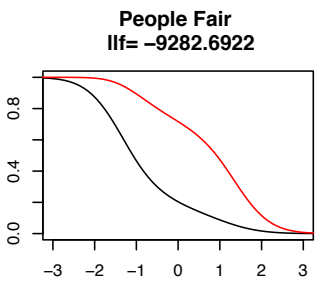

$\tau$
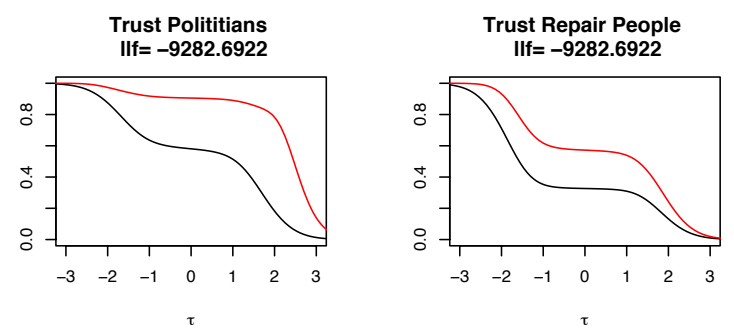

Figure 4: Estimates of item response probabilities $p\left(R_{m} \mid \tau\right)$ as functions of trust $\tau$.

Each box refers to one question (item). Trust is on the $x$-axis. Answers to each question can be 1, 2 or 3 . The probability of answering 1 is given by the distance between the $x$-axis and the lower line, the probability of answering 2 by that between the two lines, and that of answering 3 by that between 1 and the upper line. 


\section{E Tables}

Table 1: The relationship between personal and demographic characteristics and trust

\begin{tabular}{lcclcc}
\hline Variable & Coefficient & S.E. & Variable & Coefficient & S.E. \\
\hline Divorced & -0.198 & $(0.194)$ & Aragon & 0.249 & $(0.236)$ \\
Single & -0.039 & $(0.111)$ & Asturias & -0.060 & $(0.238)$ \\
Female & -0.090 & $(0.069)$ & Baleares & -0.240 & $(0.208)$ \\
Age & 0.010 & $(0.004)$ & Canarias & -0.117 & $(0.201)$ \\
Age $^{2}$ & -0.053 & $(0.026)$ & Cantabria & -0.145 & $(0.247)$ \\
Num Members $_{\text {Num Members }}^{2}$ & 0.065 & $(0.032)$ & Castilla La Mancha & 0.377 & $(0.177)$ \\
Low Income & -2.875 & $(0.941)$ & Castilla Leon & 0.071 & $(0.173)$ \\
High Income & -0.124 & $(0.149)$ & Catalunya & 0.061 & $(0.126)$ \\
Primary Degree & -0.241 & $(0.114)$ & Extremadura & 0.459 & $(0.299)$ \\
High Degree & -0.026 & $(0.093)$ & Galicia & 0.201 & $(0.170)$ \\
Unemployed & 0.432 & $(0.092)$ & Madrid & 0.358 & $(0.133)$ \\
Father Professional & -0.266 & $(0.152)$ & Murcia & -0.125 & $(0.231)$ \\
& 0.158 & $(0.124)$ & Navarra & 0.759 & $(0.291)$ \\
& & & PaisVasco & -0.155 & $(0.184)$ \\
& & & Rioja & 0.301 & $(0.262)$ \\
\hline Observations & 1156 & & Valencia & 0.002 & $(0.139)$ \\
\hline
\end{tabular}

Estimated using the European Social Survey, 2004 wave. Num Members is the number of household members. Age ${ }^{2}$ is defined as $(\text { Age - mean }(\text { Age }))^{2} / 100$ and Num Members ${ }^{2}$ as $($ NumMembers - mean (NumMembers $))^{2} / 100$. The coefficient indicates the change in the mean estimate of trust as a variable changes compared to the standardized individual. The standardized individual is a married and employed male of 38.92 years with secondary education and medium income who lives in a household with 3.35 members in Andalucia and whose father did not have a professional occupation. Standard errors in parenthesis. 
Table 2: Descriptive Statistics for the Personal and Demographic Characteristics used for Measuring Trust (ESS)

\begin{tabular}{lclc}
\hline Demographics & Mean & Region & Mean \\
\hline Single & 0.349 & Andalucia & 0.183 \\
Divorced & 0.042 & Aragon & 0.028 \\
Married & 0.599 & Asturias & 0.029 \\
Num Members & 3.349 & Baleares & 0.024 \\
& $(1.313)$ & Canarias & 0.043 \\
Unemployed & 0.056 & Cantabria & 0.011 \\
Low Income & 0.145 & Castilla La Mancha & 0.071 \\
Medium Income & 0.662 & Castilla Leon & 0.079 \\
High Income & 0.193 & Catalunya & 0.113 \\
Father Professional & 0.087 & Extremadura & 0.023 \\
Primary Degree & 0.270 & Galicia & 0.055 \\
Secondary Degree & 0.477 & Madrid & 0.136 \\
Higher Degree & 0.237 & Murcia & 0.035 \\
Female & 0.480 & Navarra & 0.015 \\
Age & 38.920 & PaisVasco & 0.051 \\
& $(17.250)$ & Rioja & 0.008 \\
& & Valencia & 0.095 \\
\hline Observations & 1156 & &
\end{tabular}

Source: European Social Survey, 2004 wave. All variables except for Num Members (number of household members) and Age are dummies. For these two continuous variables, the standard deviation is reported in parentheses. Low Income: <12000 euros/year, High Income: $>90000$ euros/year. Primary Degree is 1 if the individual has less than secondary education, and Higher Degree is 1 if the individual has a university degree or more. 
Table 3: Descriptive statistics of the survey responses used to estimate trust

\begin{tabular}{lclcl}
\hline Variable & Mean & Std. Dev. & Min & Max \\
\hline Most People can be Trusted & 1.914 & 0.773 & 1 & 3 \\
Most People Fair & 2.029 & 0.772 & 1 & 3 \\
Most People Helpful & 1.657 & 0.747 & 1 & 3 \\
Trust Legal System & 1.829 & 0.796 & 1 & 3 \\
Trust Politicians & 1.522 & 0.671 & 1 & 3 \\
Trust Repair People & 2.072 & 0.872 & 1 & 3 \\
Trust Banks & 1.875 & 0.867 & 1 & 3 \\
Trust Public Officials & 2.178 & 0.808 & 1 & 3 \\
\hline Obs
\end{tabular}

Observations 1156

Source: European Social Survey, 2004 wave. For exact wording of the questions, see Appendix B 


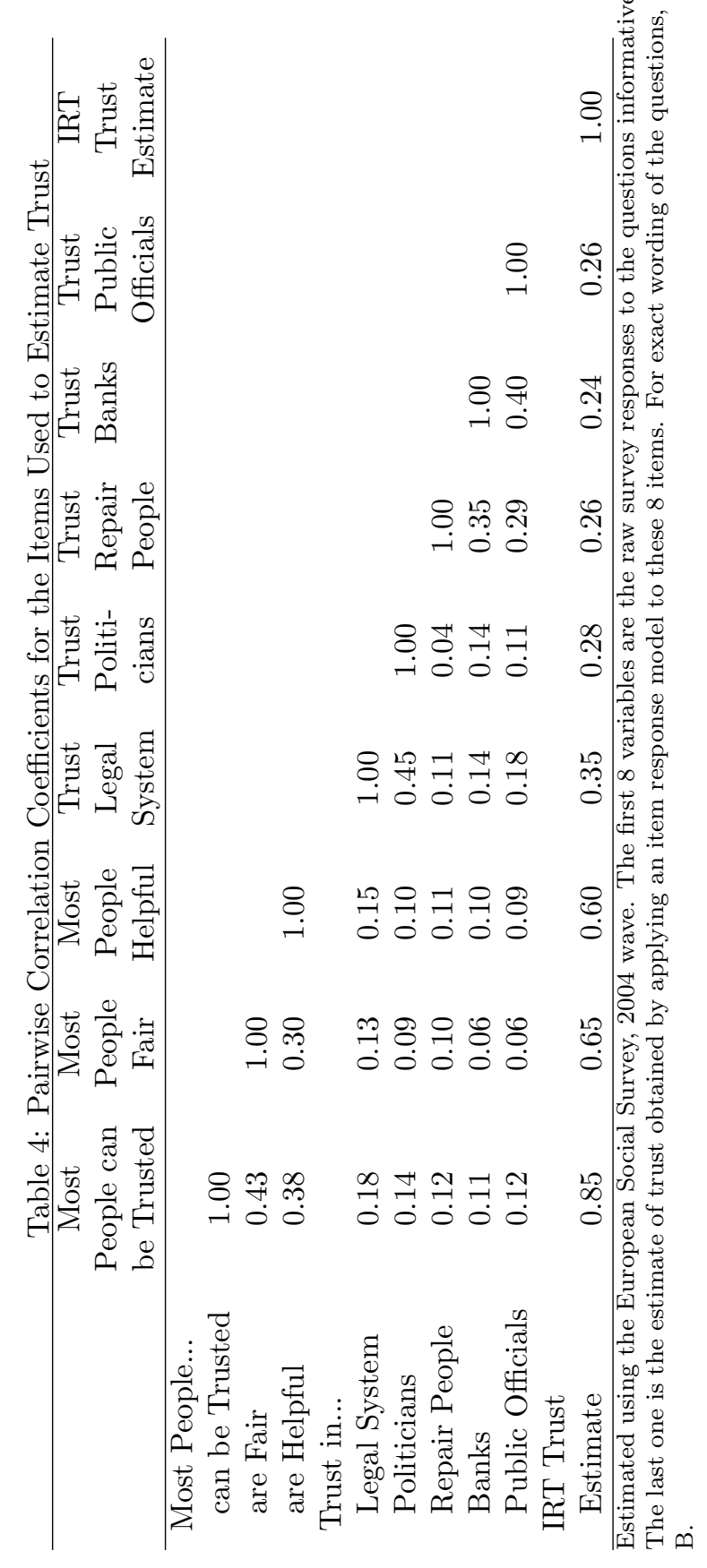


Table 5: Descriptive Statistics of the Financial Variables (EFF)

\begin{tabular}{lccccc}
\hline & Mean & Std. Dev. & \multicolumn{3}{c}{ Quantiles } \\
\cline { 4 - 6 } Value (in $€ 1,000)$ & & & 0.25 & 0.50 & 0.75 \\
\hline Total Assets (TA) & 475.3 & 4133.2 & 79.4 & 162.3 & 354.6 \\
Real Assets (RA) & 340.3 & 3125.8 & 71.8 & 148.8 & 300.0 \\
Real Estate (RE) & 254.8 & 488.9 & 65.0 & 138.0 & 275.1 \\
Financial Assets (FA) & 135.0 & 1242.3 & 1.7 & 9.0 & 41.1 \\
Risky Assets (RA) & 104.5 & 1214.9 & 0 & 0 & 6.0 \\
Non Risky Assets (NRA) & 30.5 & 95.5 & 1.5 & 6.0 & 24.0 \\
Cash (C) & 8.2 & 25.2 & 0.9 & 3.0 & 7.5 \\
\hline Value/Total Wealth & & & & & \\
\hline Real Assets/Wealth (RA/W) & 0.788 & 0.299 & 0.752 & 0.923 & 0.980 \\
Real Estate/Wealth (RE/W) & 0.737 & 0.317 & 0.639 & 0.870 & 0.970 \\
Financial Assets/Wealth (FA/W) & 0.212 & 0.299 & 0.020 & 0.077 & 0.248 \\
Risky Assets/Wealth (RA/W) & 0.051 & 0.131 & 0.000 & 0.000 & 0.023 \\
Non Risky Assets/Wealth (NRA/W) & 0.161 & 0.277 & 0.014 & 0.048 & 0.143 \\
Cash/Wealth (C/W) & 0.101 & 0.246 & 0.006 & 0.018 & 0.052 \\
\hline Observations & 4999 & & & & \\
\hline
\end{tabular}

Source: Spanish Survey of Household Finances (EFF), 2002 wave. Asset classes defined as described in Appendix C 
Table 6: Descriptive Statistics of the Variables Used in the Portfolio Choice Analysis (EFF)

\begin{tabular}{lcclcc}
\hline Variable & Mean & Std. Dev. & Variable & Mean & Std. Dev. \\
\hline Risk Aversion & 3.70 & 0.58 & Num Children & 0.90 & 1.08 \\
Income (in €1,000) & 40.4 & 76.0 & Num Members & 2.77 & 1.34 \\
Net Wealth (in $€ 1,000)$ & 463.8 & 4216.2 & Years Education & 13.64 & 7.27 \\
Female & 0.35 & & Employee & 0.32 & \\
Age Head & 57.65 & 15.62 & & & \\
\hline \multicolumn{7}{l}{ Observations } & 4999 & & & \\
Source: Spanish Survey of Household Finances (EFF), 2002 wave.
\end{tabular}


Table 7: Tobit estimation for portfolio choice

\begin{tabular}{|c|c|c|c|c|}
\hline & $\mathrm{RE} / \mathrm{W}$ & $\mathrm{FA} / \mathrm{W}$ & $\mathrm{RA} / \mathrm{W}$ & $\mathrm{C} / \mathrm{W}$ \\
\hline Trust & $\begin{array}{l}-0.035^{* *} \\
(0.016)\end{array}$ & $\begin{array}{l}0.045^{* * *} \\
(0.014)\end{array}$ & $\begin{array}{l}0.055^{* * *} \\
(0.020)\end{array}$ & $\begin{array}{l}0.024^{* *} \\
(0.011)\end{array}$ \\
\hline Risk Aversion & $\begin{array}{l}0.042^{* * *} \\
(0.007)\end{array}$ & $\begin{array}{l}-0.035^{* * *} \\
(0.006)\end{array}$ & $\begin{array}{l}-0.073^{* * *} \\
(0.007)\end{array}$ & $\begin{array}{l}-0.006 \\
(0.005)\end{array}$ \\
\hline Housing Price & $\begin{array}{l}-0.057^{* * *} \\
(0.015)\end{array}$ & $\begin{array}{l}0.076^{* * *} \\
(0.013)\end{array}$ & $\begin{array}{l}0.037^{* *} \\
(0.019)\end{array}$ & $\begin{array}{l}0.065^{* * *} \\
(0.010)\end{array}$ \\
\hline Financial Development & $\begin{array}{l}0.002^{* * *} \\
(0.000)\end{array}$ & $\begin{array}{l}-0.002^{* * *} \\
(0.000)\end{array}$ & $\begin{array}{l}-0.002^{* * *} \\
(0.000)\end{array}$ & $\begin{array}{l}-0.001^{* * *} \\
(0.000)\end{array}$ \\
\hline ln Income & $\begin{array}{l}-0.125^{* * *} \\
(0.039)\end{array}$ & $\begin{array}{l}0.074^{* *} \\
(0.035)\end{array}$ & $\begin{array}{l}0.210^{* * *} \\
(0.080)\end{array}$ & $\begin{array}{l}0.111^{* * *} \\
(0.027)\end{array}$ \\
\hline$(\ln \text { Income })^{2}$ & $\begin{array}{l}0.004 \\
(0.002)\end{array}$ & $\begin{array}{l}-0.002 \\
(0.002)\end{array}$ & $\begin{array}{l}-0.008^{* *} \\
(0.004)\end{array}$ & $\begin{array}{l}-0.005^{* * *} \\
(0.001)\end{array}$ \\
\hline ln Net Wealth & $\begin{array}{l}1.142^{* * *} \\
(0.028)\end{array}$ & $\begin{array}{l}-0.936^{* * *} \\
(0.021)\end{array}$ & $\begin{array}{l}-0.088^{* * *} \\
(0.023)\end{array}$ & $\begin{array}{l}-0.668^{* * *} \\
(0.015)\end{array}$ \\
\hline$(\ln \text { Net Wealth })^{2}$ & $\begin{array}{l}-0.045^{* * *} \\
(0.001)\end{array}$ & $\begin{array}{l}0.037^{* * *} \\
(0.001)\end{array}$ & $\begin{array}{l}0.007^{* * *} \\
(0.001)\end{array}$ & $\begin{array}{l}0.025^{* * *} \\
(0.001)\end{array}$ \\
\hline Female & $\begin{array}{l}0.026^{* * *} \\
(0.008)\end{array}$ & $\begin{array}{l}-0.010 \\
(0.007)\end{array}$ & $\begin{array}{l}-0.016 \\
(0.010)\end{array}$ & $\begin{array}{l}-0.008 \\
(0.005)\end{array}$ \\
\hline Age Head & $\begin{array}{c}0.001 \\
(0.002)\end{array}$ & $\begin{array}{l}0.004^{* *} \\
(0.002)\end{array}$ & $\begin{array}{l}-0.003 \\
(0.002)\end{array}$ & $\begin{array}{c}0.002 \\
(0.001)\end{array}$ \\
\hline Age Head ${ }^{2}$ & $\begin{array}{c}0.000 \\
(0.000)\end{array}$ & $\begin{array}{c}0.000 \\
(0.000)\end{array}$ & $\begin{array}{l}0.000 \\
(0.000)\end{array}$ & $\begin{array}{c}0.000 \\
(0.000)\end{array}$ \\
\hline Num Members & $\begin{array}{l}0.016 \text { ** } \\
(0.006)\end{array}$ & $\begin{array}{l}-0.017^{* * *} \\
(0.005)\end{array}$ & $\begin{array}{l}-0.022^{* * *} \\
(0.008)\end{array}$ & $\begin{array}{l}-0.007 \\
(0.004)\end{array}$ \\
\hline Num Children & $\begin{array}{l}-0.012 \\
(0.007)\end{array}$ & $\begin{array}{l}-0.003 \\
(0.006)\end{array}$ & $\begin{array}{l}0.017^{*} \\
(0.009)\end{array}$ & $\begin{array}{l}-0.010^{* *} \\
(0.005)\end{array}$ \\
\hline Years Education & $\begin{array}{l}-0.004^{* * *} \\
(0.001)\end{array}$ & $\begin{array}{l}0.006^{* * *} \\
(0.001)\end{array}$ & $\begin{array}{l}0.007^{* * *} \\
(0.001)\end{array}$ & $\begin{array}{l}0.003^{* * *} \\
(0.000)\end{array}$ \\
\hline Employee & $\begin{array}{l}0.080^{* * *} \\
(0.009)\end{array}$ & $\begin{array}{l}-0.011 \\
(0.008)\end{array}$ & $\begin{array}{l}-0.023^{* *} \\
(0.012)\end{array}$ & $\begin{array}{l}-0.017^{* *} \\
(0.007)\end{array}$ \\
\hline Constant & $\begin{array}{l}-5.747^{* * *} \\
(0.244)\end{array}$ & $\begin{array}{l}5.481 \text { *** } \\
(0.205)\end{array}$ & $\begin{array}{l}-1.095^{* *} \\
(0.427)\end{array}$ & $\begin{array}{l}3.796^{\text {*** }} \\
(0.156)\end{array}$ \\
\hline Observations & 4999 & 4999 & 4999 & 4999 \\
\hline
\end{tabular}

The left hand side variables are: (1) the value of real estate over total wealth, (2) the value of financial assets over total wealth, (3) the value of risky assets over total wealth and (4) the value of liquid assets over total wealth. Trust is our measure of generalized trust, computed using 8 different questions and an item response model. Risk Aversion is a self reported measure. Housing Price is the regional average house price per square meter in 2002. Financial development is proxied by the amount of private credit in the region over its GDP (see Table 11). In Income is the log of the household's income. In Net Wealth is the log of the household's net wealth. Female is a dummy equal to one if the head of the household is a female. Age is the age of the head of the household. Num members is the number of members in the household. Num children is the number of children in the household. Years of education are the number of years the head of the household attended school. Employee is a dummy variable that is equal to on if the head of the household is an employee. Standard errors in parentheses; stars indicate significance at $10\left(^{*}\right), 5\left({ }^{* *}\right)$, and $1\left(^{* * *}\right)$ percent levels, respectively. 
Table 8: Tobit estimation for portfolio choice, specification as in Guiso et al. (2008)

\begin{tabular}{|c|c|c|}
\hline & $\mathrm{RA} / \mathrm{FA}$ & $\mathrm{C} / \mathrm{FA}$ \\
\hline Trust & $\begin{array}{l}0.128^{* * *} \\
(0.040)\end{array}$ & $\begin{array}{c}0.017 \\
(0.030)\end{array}$ \\
\hline Risk Aversion & $\begin{array}{l}-0.108^{* * *} \\
(0.015)\end{array}$ & $\begin{array}{l}-0.016 \\
(0.013)\end{array}$ \\
\hline Financial Development & $\begin{array}{c}0.000 \\
(0.001)\end{array}$ & $\begin{array}{c}0.000 \\
(0.000)\end{array}$ \\
\hline Income & $\begin{array}{l}-0.019 \\
(0.015)\end{array}$ & $\begin{array}{l}0.054^{* * *} \\
(0.012)\end{array}$ \\
\hline Financial Wealth & $\begin{array}{l}0.238^{* * *} \\
(0.007)\end{array}$ & $\begin{array}{l}-0.259 \\
(0.005)\end{array}$ \\
\hline Female & $\begin{array}{c}0.012 \\
(0.022)\end{array}$ & $\begin{array}{l}-0.023 \\
(0.016)\end{array}$ \\
\hline Age Head & $\begin{array}{l}-0.008 \\
(0.005)\end{array}$ & $\begin{array}{l}-0.009 \text { ** } \\
(0.004)\end{array}$ \\
\hline Age Head ${ }^{2}$ & $\begin{array}{c}0.000 \\
(0.000)\end{array}$ & $\begin{array}{l}0.000 \\
(0.000)\end{array}$ \\
\hline Num Members & $\begin{array}{c}0.004 \\
(0.018)\end{array}$ & $\begin{array}{c}-0.013 \\
(0.013)\end{array}$ \\
\hline Num Children & $\begin{array}{c}0.008 \\
(0.020)\end{array}$ & $\begin{array}{c}-0.003 \\
(0.015)\end{array}$ \\
\hline Years Education & $\begin{array}{c}0.011^{* * *} \\
(0.002)\end{array}$ & $\begin{array}{l}-0.003 \\
(0.001)\end{array}$ \\
\hline Employee & $\begin{array}{l}-0.077^{\text {*** }} \\
(0.025)\end{array}$ & $\begin{array}{l}-0.068^{* * *} \\
(0.019)\end{array}$ \\
\hline Constant & $\begin{array}{l}-1.917^{\text {*** }} \\
(0.207)\end{array}$ & $\begin{array}{l}2.9222^{* * *} \\
(0.155)\end{array}$ \\
\hline Observations & 4999 & 4999 \\
\hline
\end{tabular}

The left hand side variables are: (1) the value of risky assets and (2) the value of liquid assets over the value of financial assets. Trust is our measure of generalized trust, computed using 8 different questions and an item response model. Risk Aversion is a self reported measure. Housing Price is the regional average house price per square meter in 2002. Financial development is proxied by the amount of private credit in the region over its GDP (see Table 11. ln Income is the log of the household's income. In Net Wealth is the log of the household's net wealth. Female is a dummy equal to one if the head of the household is a female. Age is the age of the head of the household. Num members is the number of members in the household. Num children is the number of children in the household. Years of education are the number of years the head of the household attended school. Employee is a dummy variable that is equal to on if the head of the household is an employee. Standard errors in parentheses; stars indicate significance at $10\left(^{*}\right), 5\left({ }^{* *}\right)$, and $1\left(^{* *}\right)$ percent levels, respectively. 
Table 9: Tobit estimation for portfolio choice, comparing different measures of trust

\begin{tabular}{|c|c|c|c|c|}
\hline \multirow{3}{*}{$\begin{array}{l}\text { Trust } \\
\quad \text { (IRT measure) }\end{array}$} & $\mathrm{RE} / \mathrm{W}$ & $\mathrm{FA} / \mathrm{W}$ & $\mathrm{RA} / \mathrm{W}$ & $\mathrm{C} / \mathrm{W}$ \\
\hline & $-0.035^{* *}$ & $0.045^{* * *}$ & $0.055^{* * *}$ & $0.024^{* *}$ \\
\hline & $(0.016)$ & $(0.014)$ & $(0.020)$ & $(0.011)$ \\
\hline \multirow{3}{*}{$\begin{array}{l}\text { Trust } \\
\text { (single question) }\end{array}$} & $\mathrm{RE} / \mathrm{W}$ & $\mathrm{FA} / \mathrm{W}$ & $\mathrm{RA} / \mathrm{W}$ & $\mathrm{C} / \mathrm{W}$ \\
\hline & -0.003 & 0.024 & 0.031 & 0.012 \\
\hline & $(0.016)$ & $(0.015)$ & $(0.021)$ & $(0.012)$ \\
\hline \multirow{3}{*}{$\begin{array}{l}\text { Trust } \\
\text { (mean of responses) }\end{array}$} & $\mathrm{RE} / \mathrm{W}$ & $\mathrm{FA} / \mathrm{W}$ & $\mathrm{RA} / \mathrm{W}$ & $\mathrm{C} / \mathrm{W}$ \\
\hline & $-0.073^{* *}$ & $0.081^{* *}$ & $0.153^{* * *}$ & 0.025 \\
\hline & $(0.031)$ & $(0.034)$ & (0.049) & (0.027) \\
\hline \multirow{3}{*}{$\begin{array}{l}\text { Trust } \\
\text { (PCA measure) }\end{array}$} & $\mathrm{RE} / \mathrm{W}$ & $\mathrm{FA} / \mathrm{W}$ & $\mathrm{RA} / \mathrm{W}$ & $\mathrm{C} / \mathrm{W}$ \\
\hline & $-0.024^{* *}$ & $0.023^{* *}$ & $0.041^{* * *}$ & 0.007 \\
\hline & (0.011) & (0.009) & $(0.014)$ & $(0.007)$ \\
\hline \multirow{3}{*}{$\begin{array}{l}\text { Trust } \\
\quad \text { (in banks) }\end{array}$} & $\mathrm{RE} / \mathrm{W}$ & FA/W & $\mathrm{RA} / \mathrm{W}$ & $\mathrm{C} / \mathrm{W}$ \\
\hline & -0.027 & 0.004 & -0.024 & 0.003 \\
\hline & $(0.014)$ & $(0.013)$ & $(0.019)$ & $(0.003)$ \\
\hline Sample Size & 4999 & 4999 & 4999 & 4999 \\
\hline
\end{tabular}

The left hand side variables are: (1) the value of real estate over total wealth, (2) the value of financial assets over total wealth, (3) the value of risky assets over total wealth and (4) the value of liquid assets over total wealth. Each specification includes a different measure of trust as an independent variable: Trust (IRT measure) is the measure of generalized trust computed using 8 questions and the item response model. This specification is the same as that in Table 7 Trust (single question) is a measure of generalized trust computed using the question "Generally speaking, would you say that most people can be trusted?" Trust (mean of responses) is a measure of generalized trust computed using the mean of the responses to all 8 questions on trust. Trust (PCA measure) is a measure of generalized trust computed using the first component of a principal components analysis on the 8 questions on trust. Trust in banks is computed using the question "How much do you trust financial companies such as banks or insurers?" (See footnote 18 for more details on how these measures have been computed.) In all specifications, we also control for the same variables as in Table 7 (coefficients not shown). Standard errors in parentheses; stars indicate significance at $10(*)$, $5\left({ }^{* *}\right)$, and $1\left({ }^{* * *}\right)$ percent levels, respectively. 
Table 10: Tobit estimation for portfolio choice: The Role of Education and Wealth

\begin{tabular}{|c|c|c|c|c|}
\hline & $\mathrm{RE} / \mathrm{W}$ & $\mathrm{FA} / \mathrm{W}$ & $\mathrm{RA} / \mathrm{W}$ & $\mathrm{C} / \mathrm{W}$ \\
\hline \multirow[t]{2}{*}{ Trust } & $-0.066^{* *}$ & $0.073^{* * *}$ & $0.146^{* * *}$ & 0.034 \\
\hline & $(0.029)$ & $(0.026)$ & $(0.043)$ & $(0.021)$ \\
\hline \multirow[t]{3}{*}{ Trust $\times$ Education } & $0.002^{* *}$ & $-0.002 *$ & $-0.005^{* *}$ & -0.001 \\
\hline & $(0.001)$ & $(0.001)$ & $(0.002)$ & $(0.001)$ \\
\hline & $\mathrm{RE} / \mathrm{W}$ & $\mathrm{FA} / \mathrm{W}$ & $\mathrm{RA} / \mathrm{W}$ & $\mathrm{C} / \mathrm{W}$ \\
\hline \multirow[t]{2}{*}{ Trust } & $-0.404^{* * *}$ & $0.507^{* * *}$ & $0.522^{* * *}$ & $0.023^{* * *}$ \\
\hline & $(0.094)$ & $(0.079)$ & $(0.114)$ & $(0.059)$ \\
\hline \multirow[t]{2}{*}{ Trust $\times$ Education } & 0.000 & 0.001 & $-0.004^{*}$ & $0.001 *$ \\
\hline & $(0.002)$ & $(0.001)$ & $(0.002)$ & $(0.001)$ \\
\hline \multirow[t]{2}{*}{ Trust $\times$ Wealth } & $0.030^{* * *}$ & $-0.040^{* * *}$ & $-0.032^{* * *}$ & $-0.018^{* * *}$ \\
\hline & $(0.008)$ & $(0.007)$ & $(0.009)$ & $(0.005)$ \\
\hline Observations & 4999 & 4999 & 4999 & 4999 \\
\hline
\end{tabular}

The left hand side variables are: (1) the value of real estate over total wealth, (2) the value of financial assets over total wealth, (3) the value of risky assets over total wealth and (4) the value of liquid assets over total wealth. Trust is the measure of generalized trust (computed using 8 questions). Trust $\times$ Education is an interaction between our measure of trust and the number of years the head of the household attended school. Trust $\times$ Wealth is an interaction between our measure of trust and the log of net wealth held by the household. In addition, we control for the same variables as in Table 7 Standard errors in parentheses; stars indicate significance at $10\left({ }^{*}\right), 5\left({ }^{* *}\right)$, and $1\left(^{* * *}\right)$ percent levels, respectively. 
Table 11: Instruments and Variables with Regional Variation

\begin{tabular}{lccccc}
\hline & $\begin{array}{c}\text { Financial } \\
\text { Development }\end{array}$ & $\begin{array}{c}\text { Regional } \\
\text { Housing Price }\end{array}$ & $\begin{array}{c}\text { Literacy Rate } \\
\text { in 1887 }\end{array}$ & $\begin{array}{c}\text { Early Political } \\
\text { Institutions }\end{array}$ & $\begin{array}{c}\text { Charity Org. } \\
\text { in 1920 }\end{array}$ \\
\hline Andalucía & 77.00 & 914.97 & 26.25 & 1 & 0.118 \\
Aragon & 72.72 & 1013.62 & 29.00 & 3 & 0.039 \\
Asturias & 69.54 & 985.89 & 40.50 & 1 & 0.021 \\
Baleares & 86.95 & 1525.95 & 21.00 & 1 & 0.058 \\
Canarias & 67.16 & 1218.04 & 18.50 & 1 & 0.018 \\
Cantabria & 69.26 & 1183.22 & 40.50 & 1 & 0.021 \\
Castilla Leon & 67.12 & 1012.56 & 48.50 & 1 & 0.236 \\
Castilla La Mancha & 64.91 & 681.00 & 29.00 & 1 & 0.042 \\
Catalunya & 89.56 & 1553.95 & 32.00 & 3 & 0.182 \\
Extremadura & 66.76 & 557.25 & 20.00 & 1 & 0.027 \\
Galicia & 65.13 & 800.08 & 27.50 & 1 & 0.051 \\
Madrid & 121.37 & 1973.78 & 62.00 & 1 & 0.294 \\
Murcia & 82.13 & 747.40 & 21.00 & 1 & 0.018 \\
Navarra & 74.84 & 1290.22 & 45.50 & 1 & 0.021 \\
Pais Vasco & 87.16 & 1900.44 & 48.50 & 1 & 0.042 \\
Rioja & 79.92 & 1061.41 & 45.50 & 1 & 0.021 \\
Valencia & 84.48 & 877.26 & 21.00 & 3 & 0.097 \\
\hline
\end{tabular}

The Regional Housing Price is the average regional house price per square meter in 2002, calculated by the Ministry of Development and Public Works (Ministerio de Fomento). Financial development is proxied by the amount of private credit in the region over its GDP as reported by the National Statistics Institute (INE). Literacy rate is the percentage of the population over 10 years able to read and write in 1877, from Nunez (1990). Early political institutions is a measure of constraints on the executive, from Tabellini (2005). Charity Organizations is 1000 times the amount of charity organizations per capita existing in each region in 1920 as reported in the Anuario Estadístico de España published by INE. 
Table 12: IV Tobit estimation for portfolio choice.

\begin{tabular}{|c|c|c|c|c|c|}
\hline Dependent Variable: & Trust & $\mathrm{RE} / \mathrm{W}$ & $\mathrm{FA} / \mathrm{W}$ & $\mathrm{RA} / \mathrm{W}$ & $\mathrm{C} / \mathrm{W}$ \\
\hline Trust & & $\begin{array}{l}0.080 * \\
(0.046)\end{array}$ & $\begin{array}{l}0.101^{* *} \\
(0.045)\end{array}$ & $\begin{array}{l}0.297^{* * *} \\
(0.060)\end{array}$ & $\begin{array}{c}0.008 \\
(0.034)\end{array}$ \\
\hline Literacy & $\begin{array}{l}0.010^{* * *} \\
(0.001)\end{array}$ & & & & \\
\hline Institutions & $\begin{array}{l}0.015 \text { *** } \\
(0.003)\end{array}$ & & & & \\
\hline Charity Organizations & $\begin{array}{l}-0.004 \\
(0.066)\end{array}$ & & & & \\
\hline p-value (excluded) & 0.000 & & & & \\
\hline Wald Test Exogeneity & & 0.335 & 0.121 & 0.000 & 0.150 \\
\hline Observations & & 4999 & 4999 & 4999 & 4999 \\
\hline \multicolumn{6}{|c|}{$\begin{array}{l}\text { The first column reports first-stage results. In the remaining columns, the left hand side } \\
\text { variables are: (1) the value of real estate over total wealth, }(2) \text { the value of financial assets } \\
\text { over total wealth, (3) the value of risky assets over total wealth and }(4) \text { the value of liquid assets } \\
\text { over total wealth. Trust is the measure of generalized trust (computed using } 8 \text { questions and } \\
\text { an item response model) and is instrumented using Literacy rate, Early political institutions } \\
\text { and Charity Organizations (see Table } 11 \text {. In addition, we control for the same variables as } \\
\text { in Table } 7 \text { p-value (excluded) is the p-value associated to the F-test of significance of the } \\
\text { exogenous variables. The Wald test for exogeneity tests if the residuals of the OLS regression } \\
\text { of trust on the instruments are significant when included in the regression of portfolio share } \\
\text { on trust. Values higher than } 0.05 \text { are weak evidence against the null hypothesis that trust is } \\
\text { exogenous. Standard errors in parentheses; stars indicate significance at } 10\left({ }^{*}\right), 5\left({ }^{* *}\right) \text {, and } 1 \\
(* *) \text { percent levels, respectively. }\end{array}$} \\
\hline
\end{tabular}

\section{References}

Amemiya, T. (1974) The nonlinear two-stage least-squares estimator, Journal of Econometrics 2, 105-110.

Barberis, N., Huang, M. and Santos, T. (2001) Prospect Theory and Asset

Prices, Quarterly Journal of Economics 116, 1-53.

Bayer, P. J., Bernheim, B. D. and Scholz, J. (2009) The Effects of Financial Education in the Workplace: Evidence from a Survey of Employers, Economic Inquiry 47, 605-624.

Bernheim, B. D. and Garrett, D. M. (2003) The Effects of Financial Education in the Workplace: Evidence from a Survey of Households, Journal of Public

Economics 87, 1487-1519. 
Bover, O. (2004) The Spanish Survey of Houehold Finances (EFF): description and methods of the 2002 wave, Banco de España Occasional Paper 0409.

Bover, O., Martinez-Carrasco, C. and Velilla, P. (2005) The Wealth of Spanish Households: A Microeconomic Comparison with the United States, Italy and the United Kingdom, Banco de España Economic Bulletin.

Brueckner, J. (1997) Consumption and Investment Motives and the Portfolio Choices of Homeowners, Journal of Real Estate Finance and Economics 15, 159-180.

Campbell, J. and Cocco, J. (2003) Household Risk Management and Optimal Mortgage Choice, Quarterly Journal of Economics 18, 1449-1494.

Carneiro, P., Hansen, K. and Heckman, J. (2003) Estimating distributions of treatment effects with an application to the returns to schooling and measurement of the effects of uncertainty on college choice, International Economic Review 44, 361-422.

Cocco, J. (2004) Portfolio Choice in the Presence of Housing, Review of Financial Studies 18, 535-567.

Cuoco, D. and Liu, H. (2000) Optimal consumption of a divisible durable good, Journal of Economic Dynamics and Control 24, 561-614.

Deaton, A. (1991) Saving and Liquidity Constraints, Econometrica 59, 12211248 .

Dominitz, J. and Manski, C. (2005) Measuring and Interpreting Expectations of Equity Returns, NBER Working Paper 11313.

Duarte, J., Siegel, S. and Young, L. (2010) Trust and Credit, mimeo.

Duflo, E. and Saez, E. (2002) Participation and investment decisions in a retirement plan: the influence of colleagues' choices, Journal of Public Economics 85, 121-148.

Faig, M. and Shum, P. (2002) Portfolio choice in the presence of personal illiquid projects, Journal of Finance 57, 303-328. 
Fatih, M., Kalemly-Ozcan, S. and Sorensen, B. (2007) Financial Integration within EU Countries: The Role of Institutions, Confidence and Trust, NBER Working Paper 13440.

Flavin, M. and Yamashita, T. (2002) Owner-Occupied Housing and the Composition of the Household Portfolio, American Economic Review 92, 345-362.

Glaeser, E., Laibson, D. and Sacerdote, B. (2002) An Economic Approach to Social Capital, Economic Journal 114, F437-F458.

Green, W. (2003) Econometric Analysis, Prentice Hall, Upper Saddle River, NJ.

Guiso, L. and Japelli, T. (2005) Awareness and Stock Market Participation, Review of Finance $\mathbf{9}, 537-567$.

Guiso, L., Sapienza, P. and Zingales, L. (2004) The Role of Social Capital in Financial Development, American Economic Review 94, 526-556.

Guiso, L., Sapienza, P. and Zingales, L. (2008) Trusting the Stock Market, Journal of Finance 63, 2557-2600.

Guiso, L., Sapienza, P. and Zingales, L. (2009) Cultural Biases in Economic Exchange?, Quarterly Journal of Economics 124, 1095-1131.

Heaton, J. and Lucas, D. (2000) Portfolio Choice in the Presence of Background Risk, Economic Journal 110, 1-26.

Heckman, J., Stixrud, J. and Urzua, S. (2006) The Effects of Cognitive and Noncognitive Abilities on Labor Market Outcomes and Social Behavior, Journal of Labor Economics 24, 411-482.

Hong, H., Kubik, J. and Stein, J. (2004) Social interaction and stock market participation, Journal of Finance 59, 137-163.

Hu, X. (2005) Portfolio Choices for Home Owners, Journal of Urban Economics 58, 114-136.

Newey, W. K. (1987) Efficient estimation of limited dependent variable models with endogenous explanatory variables, Journal of Econometrics 36, 231-250. 
Nunez, C. (1990) Literacy and Economic Growth in Spain, 1860-1977, in: G. Tortella (ed.), Education and Economic Development since the Industrial Revolution, Generalitat Valenciana, Valencia.

Puri, M. and Robinson, D. (2007) Optimism and Economic Choice, Journal of Financial Economics 86, 71-99.

Putnam, R. (2000) Bowling alone: the collapse and revival of American community, Simon and Schuster, New York.

Rodriguez, G. (2008) Multilevel Generalized Linear Models, in: J. de Leeuw and E. Meijer (eds.), Handbook of Multilevel Analysis, Springer, New York.

Schennach, S. M. (2004) Estimation of Nonlinear Models with Measurement Error 72, 33-75.

Spady, R. (2007) Semiparametric methods for the measurement of latent attitudes and the estimation of their behavioural consequences, CEMMAP Working Paper CWP26/07.

Steele, F. and Goldstein, H. (2007) Multilevel Models in Psychometrics, in: C. Rao and S. Sinharay (eds.), Handbook of Statistics. Psychometrics, volume 26, pages 401-418, Elsevier North-Holland, Amsterdam.

Tabellini, G. (2005) Culture and institutions: economic development in the regions of Europe, IGIER Working Paper Series 292.

Takane, Y. and de Leeuw, J. (1987) On the relationship between item response theory and factor analysis of discretized variables, Psychometrika 52, 393-408. Vissing-Jorgensen, A. (2002) Towards an Explanation of Household Portfolio Choice Heterogeneity: Nonfinancial Income and Participation Cost Structures, NBER Working Paper 8884.

Vissing-Jorgensen, A. (2003) Perspectives on Behavioral Finance: Does "Irrationality" Disappear with Wealth? Evidence from Expectations and Actions, NBER Macroeconomics Annual 18, 139-194. 
Yao, R. and Zhang, H. (2005) Optimal Consumption and Portfolio Choices with Risky Housing and Borrowing Constraints, Review of Financial Studies 18, 197-239. 